\title{
INTEGRATIVE PSYCHOLOGY: THE RETURN TO THE SUBJECT OF PSYCHOLOGY
}

\author{
Vladimir V. Kozlov \\ Yaroslavl State Demidov University \\ Yaroslavl
}

The article analyzes the basic paradigms of psychology and put forward the thesis of the expansion of the subject area of psychology in the course of historical development, and describes the main features of integrative psychology. Highlighted in the article the new paradigm of psychology (transpersonal, communicative, integrative), make it possible to trace a vector of development of modern psychology as a multidimensional communicative environment that has intention to make a perusal of psychic reality.

Keywords: physiological, psychoanalytical, behavioral and existential-humanistic, transpersonal, communicative, integrative paradigm of psychology, subject of psychology.

Modern state of psychology is characterized by confrontation between many schools, trends, new methodological and psychotechnic approaches to understanding of the subject and objectives of the ancient science of psyche. No doubt, experience proves that the very discussion about the subject of psychology is in many ways a mediocre and thankless job. And starting this article I am well aware of all the risks it may bring. But in spite of this, I would like to get the reader acquainted with some ideas that were not only my subjects of reflection, but also mental discoveries that made it possible to gain a clearer understanding of the diverse subject of psychology (Kozlov, 2005; 2007).

We can distinguish seven basic paradigms in understanding the subject of psychology:

1. Physiological;

2. Psychoanalytic;

3. Behavioral;

4. Existential and humanistic;

5. Transpersonal;

6. Communicative;

7. Integrative.

Let us have a closer look at them. 


\section{Physiological psychology}

No doubt, any psychologist who once dealt with the history of the subject of psychology may not agree with the seven-wave psychology classification. Many may say that the first subjects of psychology were the contents and acts of consciousness and that the introspective trend and philosophical reflection on the subject of psychology as such bear the palm in determining the subject. On the one hand, the introspective trend is well represented by famous schools founded by W. Wun$\mathrm{dt}$, structural psychology of E. Titchener, act psychology of F. Bretano, the Wurzburg school, as well as by the Russian researchers L.M. Lopatin and G.I. Chelpanov. But on the other hand, we must realize that for many thousands of years the method of sophisticated introspection was employed by spiritual traditions for self-understanding. All attempts of introspectionalists to overcome unreliability of everyday non-scientific self-observation by special training that formed the skill of self-report on what the person was aware of in the moment of stimulus presentation seem ridiculous as compared to trained za-zen and vipassana practices. Introspection was the basis for many philosophical, theological, and spiritual models of reality, but not for scientific psychology (Kozlov, 2007).

That is exactly why we consider physiological psychology to be the beginning of psychology, and physiological acts and laws to be the first subject of psychology. The very emergence of scientific psychology is associated with rapid development of natural sciences, particularly physiology and medicine. Moreover, the first matrices of objective psychological research were, indeed, physiological and medical.

It is known that $\mathrm{W}$. Wundt, who set up the first experimental psychological laboratory, is considered to be the founder of scientific psychology. We can safely suggest that the first experiments in psychology were phychophysiological rather than psychological. It was not without reason that the term "psychophysiology" was used along with the notion of "physiological psychology" for designation of a wide range of psyche research works that were based on precise objective physiological methods of sensory, motor, vegetative reactions reporting. Therefore, we can assume with confidence that the first subject of psychology is psychophysiology of sensory organs, sensations, and perceptions, and the first experiments with this subject (G.T. Fechner) are devoted to measurement of sensations depending on the degree of physical stimulus and perception threshold and to psychophysical grading.

We should not think that physiological psychology, having provided psychology with the first subject (psychophysiology of sensory organs) and a scientific method (experiment), disappeared from the scientific stage. Its further development was so successful that it encompassed all possible phenomena, properties, states, and processes of the psyche: psychophysiology of movement, activity, voluntary actions, attentiveness, memory, and learning; speech and thinking, motivation and emotions; dreams, stress psychophysiology, psychophysiology of functional states, differential psychophysiology, which studies physiological grounds for individual and psychological differences, etc.

Moreover, it is physiological psychology that became a cornerstone for materialistically oriented Soviet psychology, which relying on the concept of nervous system properties (that goes back to I.P. Pavlov's works on the types of higher nervous activity) developed an integrated universal model of psychological science (Kozlov, 2007).

\section{Psychoanalysis}

The second wave and the second step in the development of the subject of psychology were produced by psychoanalysis, which was founded at the turn of the XIX century by Z. Freud, Austrian psychiatrist and psychologist (Freud, 1991a; 1991b). It is known that originally it developed as a method of neurosis treatment; then it turned into a general psychological theory that focused on driving forces of mental life, motives, drives, and values; eventually, it became one of the most influential trends in psychology of the XX century. Psychoanalysis is the first psychological theory that chose personality as its subject and tried to explain its dynamics. Freud not only did choose personality as the subject of psychological research and therapy, but also was the first to attempt to reveal it in dynamic (as the product of relationship between different forces), energetic (energetic relationship in a real mental process), and structural (place and role of the conscious, subconscious, and unconscious: Id, Ego, Superego) aspects.

In the context of our article, the meanings Freud gave to these three aspects of personality functioning are not important to us. Moreover, 
more than one kiloton of scientific literature is devoted to criticism and analysis of Freud's heritage. We find three fundamental theses showing the pioneering character of psychoanalysis as the second wave of the development of psychology to be most significant to us:

A) a new subject - broadening the subject of psychology up to a topologically, dynamically, and energetically complex personality. And the main task of psychoanalysis is to help a suffering person understand a true reason of sufferings concealed in the unconscious, recall forgotten traumatic experiences, make them conscious and sort of live through them once again, which results in a catharsis effect. To identify the concealed, to make the unconscious contents conscious, and, therefore, available for comprehension and partial control - that is the goal of psychoanalysis as a psychological method.

B) a new attitude to the subject - introducing of a new subject-subject dialogic attitude to personality as against a subject-object medical and biologic attitude in physiological psychology. General principles and goals of psychoanalysis (E. Fromm) reveal this very backbone of the second wave of psychology:

- the goal of psychoanalytical treatment is adaptation of a client. Adaptation is understood as human ability to behave the way most people do in a given culture, and socially appreciated models of behavior are seen as mental health criteria. This therapy is exclusively social-adaptation-oriented, and it can reduce sufferings of a neurotic to a medium level. "An adapted person" represents himself as a subject of sale, and there is no stability and clarity in it except for the need to give pleasure and willingness to change roles. Betrayal of Self and human values result in inner void and instability and, eventually, in psychogenic illnesses.

- the goal of psychoanalysis is optimal development of personal abilities and actualization of individuality. It is oriented to soul healing and gaining mental health, which is inseparable from the man's main problem, i.e. pursuing goals of life: good morals, integrity, and ability to love. This therapy helps gain inner strength, integrity, selfconfidence, judgment ability and objective assessment, which makes it less assailable and dependant on changing times and other people's opinion.

In real psychoanalytical practice, there is no clear distinction between general principles of therapy. Both principles are employed in combination, though the ratio is different in each particular case. Understanding of this ratio and focusing on one of the principles can increase effectiveness of psychological assistance.

Whereas within the framework of physiological psychology we deal with man as the subject of research, control, therapy, treatment, and manipulation, within the framework of psychoanalysis we already see a partner for interaction who has his own opinion and who is free to decide and to choose, including his choice to play a psychotherapeutic analytical game or not.

C) new psychological methods of interaction with the subject. In the context of this aspect we can state that psychoanalysis gave rise to new psychological-in-character methods of interaction with the subject: association method, sleep analysis and dreams interpretation, analysis and interpretation of various faulty and undesigned (accidental) symptomatic actions, which take place in everyday life (Kozlov 2003; 2007; Feydiman, and Freyger, 1996; Fromm, 1993).

\section{Behaviorism}

The third wave of psychology is behaviorism, a trend in American psychology of the $20^{\text {th }}$ century, which emerged in 1913 with the publication of the article "Psychology as the Behaviorist Views it" by American psychologist J. Watson. It is known that Watson said that psychology can be considered a science only in case it works out an objective approach to phenomena under consideration. Therefore, psychology must limit its scope to description and quantitative assessment of behavior patterns people perform in certain situations. Thus, the third subject of psychology is behavior.

No doubt, emergence of any trend, and a "new wave" of psychology as well, is commissioned by society; it is triggered by some "call of life", by needs of a social space. In this respect, psychoanalysis is a response to appearance of personality that is not identified with community and that for the first time tasted loneliness and independence in taking decisions and neurotic responsibility for its own choice and fate.

As for the third wave, emergence of behaviorism concurred with the mushroom industrial growth and the process of sophistication of management and educational systems in the USA. The then existing 
social and economic context could only appreciate such views on man according to which his behavior takes this or that form depending on a situation. This theory easily found its practical application in introduction of conveyors, development of advertisements, programmed education, and effective management systems for complex systems, including social ones.

Originally, it was a sound success-oriented teaching, which focused on effective behavior and activities in complicated social situations that were free from odd and inexplicable chimeras of consciousness, awareness, experience, suffering, etc.

Behavior is defined as a system of responses, and relation between stimulus $\mathrm{S}$ and response $\mathrm{R}$ is stated as the unit of behavior analysis: the $\mathrm{S}-\mathrm{R}$ scheme was put forward as descriptive and explanatory one, and, according to it, impact (stimulus) $\mathrm{S}$ causes some kind of behavior (response) $\mathrm{R}$ and the nature of response is determined by stimulus alone. All responses can be divided into hereditary (reflexes, physiological reactions and simple emotions) and learned (habits, thinking, speech, complex emotions, social behavior), and they are formed when hereditary responses triggered by unconditional stimuli are tied to (conditioned by) new (conditional) stimuli.

We are not going to make a detailed analysis of an almost centennial development of behavioral ideas that are related to such authoritative scientists as E. Thorndike, I. Pavlov, E. Tolman, and F.B. Skinner. The latter worked out the concept of operant conditioning and introduced an essential correction into the classical scheme by inserting an intermediate element (intervening variables), and the scheme became the following: $\mathrm{S}-\mathrm{V}-\mathrm{R}$.

In the context of our article, it is extremely important that it is objectively recorded characteristics of behavior induced by external impacts and environmental stimulus factors themselves that are seen as the subject of psychology in behaviorism rather than man's subjective world. Thus, the subject of psychology extended up to such phenomena as learning, action, socialization, social behavior determinants, etc. Psychology then ceased to be individual. Its subject extended up to socioenvironmental factors, and to some approximation by means of these factors it implemented its scientific program, i.e. ability to control behavior (Kozlov, 2007; Feydiman, and Freyger, 1996).

\section{Existential and humanistic psychology}

The fourth wave of psychology is the existential and humanistic trend in psychology, which is associated with further broadening of the subject of psychology - up to good morals and existential problems of human life in the world.

World War II gave a major lesson: knowledge of physiology and personality and effective simulation of human behavior are not sufficient; the revival of higher values is needed, otherwise man becomes a super beast able to butcher millions of people and destroy a bulk of social and cultural values just for nothing.

Finally, psychology focused on the problems which were naturally interwoven into a communal way of life and solutions to which were a priority for the ethic and moral component of religion and spiritual traditions. Psychology took as a research subject the problems of time, life and death, freedom, responsibility and choice, communication, love and loneliness, meaning and meaninglessness of existence, quest for the meaning of existence, moral standards and value systems of personality, compassion, cooperation, fellowship, help and support, and humanism.

L. Binswanger, M. Boss, G. Bugental, F. Barron, K. Buhler, S. Jurard, A. Maslow, R. May, E. Minkowski, C. Rogers, V. Frankl, etc. objectified a new semantic field of psychology associated with mastering of moral standards, empathy, learning the so-called facilitating behavior and avoided opposition of altruism and egoism (implying either humiliating victimhood or interested selfishness).

Having restored the ethic values of world religions and spiritual Eastern traditions, European mystic teachings of philosophy and esoterics, in the 50 -ies of the $20^{\text {th }}$ century psychology restored human being as the main value and yardstick of everything and declared that the principle subject of psychology is personality as a complex unique integral system which is something given a priori but capable of self-actualization.

The thesis "God is within you" transformed into the belief that each person can reach his prime provided he has a chance to choose and guide his fate himself, and the ethical principle of "love thy neighbor" (Christianity), "Loving kindness" (Buddhism) turned into an optimistic view of "peace and love".

Thus, we can view existential and humanistic psychology as the new moral psychology that opposed itself to behaviorism and Freudism, 
which made special reference to personality's dependence on its past, and regarded striving for future, for self-fulfillment (particularly creative potential), for strengthening confidence and opportunity to reach "Ideal Self" to be most essential.

In a sense it went far beyond some religious and ethic teachings by:

- elaborating the idea of the need of ultimate creative self-actualization, which means true mental health, and

- choosing higher values, personality self-actualization, creativity, love, freedom, responsibility, autonomy, mental health, and interpersonal communication ethics as the subject of psychology.

Within the framework of this trend we can discover a new stand of psychologist in relation to his client.

The most important here is the client with his motives and goals who develops his constructivity rather than adapts himself to environment or strives for conformal behavior.

And psychologist is a wise mentor who is completely plunged in guru ahimsa, in a range of sacred duties of teacher in relation to his disciple, and his main function is to arrange cordial emotional atmosphere, effective supporting environment where its easier for him to organize his inner "phenomenological" world and gain wholeness of his own personality, realize the meaning of his existence, solve his life koan and unpack basic existentials (Frankl, 1990; Kozlov, 2004; 2007; Maslow, 1997; Maykov, and Kozlov, 2004; Mazilov, 2007; Rogers, 1997).

\section{Transpersonal psychology}

No doubt the fifth wave - transpersonal psychology - is the utmost manifestation of the breadth of the subject of psychology.

The rise and development of transpersonal psychology is closely connected to modern global issues and civilizational processes. Dramatic changes taking place throughout the world, shaking all social groups and affecting everyone have a fundamental dimension that escaped philosophic and psychological analyses until recently. The Earth's civilization is entering a new phase of its development that can be characterized as conscious evolution, when mankind is being transformed at a fast pace by integration of knowledge and efforts of Western technologies of the outer and Eastern technologies of the inner.
Trends for social life renewal of 60 -ies and 70 -ies of the $20^{\text {th }}$ century, which manifested themselves as youth counterculture and "pilgrimage to the East" alternatives to the official establishment, today have proven to be incorporated into large social projects for humanization of culture through self-actualization and self-improvement. Movements for humanization and revolution of consciousness turned out to be among the most significant components of mass culture, which makes current situation unique. They call for radical reforms in all spheres of life of modern Western civilization. Transpersonal psychology appears to be the intellectual leader of this universal striving for boundless development, which makes expert evaluation of ancient and contemporary methods of holistic and spiritual improvement and renders the wisdom of the ancients on transcendency art in the language of modern Western culture.

Transpersonal psychology is a trend that emerged in late 60-ies of the $20^{\text {th }}$ century in the USA based on a Transpersonal Project in Culture. The founders of the trend were such well-known philosophers, psychologists, and psychotherapists as A. Maslow, S. Grof, A. Watts, M. Murphy, A. Sutich, etc. The range of theoretical problems of this trend was developed by psychologists from psychoanalytical, humanistic, and transpersonal trends, as well as the leading scientists and thinkers from other fields of knowledge: W. James, Z. Freud, O. Rank, C.G. Jung, C. Rogers, C. Tart, K. Wilber, K. Pribram, D. Chew, F. Capra, etc. (James, 1993; Nalimov, 1989; Rogers, 1997; Wilber, 1991; Freud, 1991a; Fromm, 1993). The fifth wave of psychology chose as the subject of psychology areas beyond the ordinary, personal, individual level of experience, where the sense of self-identity transcends individual, or personal, Self and embraces mankind as a whole, life, Spirit, and universe. In accordance with the studies carried out by the founders of transpersonal paradigm of psychology (W. James, C.G. Jung, R. Assagioli, A. Maslow, K. Wilber, S. Grof, etc.), human consciousness is developing in the following way: first, differentiation and independence of an active ego and, afterwards, transcending of attachment to the ego.

Thus, we can designate the fifth wave as a psychological teaching on transpersonal experiences, their nature, various forms, causes and effects, as well as on manifestations in psychology, philosophy, real life, art, culture, life style, religion, etc. that they inspire and that attempt to induce, manifest, apply them or gain an insight into them. 
No doubt, neither the need to transcend nor the transcendental itself involving ontological dimensions of human existence (God, Universe, the sacred and numinous) disappeared from human life during the rise and development of the first four waves. But to become a science, psychology sacrificed the Spirit and the sacred first, then immolated the soul and consciousness eventually finding itself stripped to physiological act.

And after it had gained strength and intellectual power, psychology drew back all possible phenomenology of mental life, including the transpersonal project, which is the basic approach in world spiritual and philosophic traditions, otherwise, "empty is the nut of existence" of human consciousness and has always been (Kozlov, 2000).

Revealing the subject of the fifth wave more thoroughly, we will discover its specific and unique features. Transpersonal experience is taken as the subject, and phenomenologically it comes to the following (S. Grof):

- Temporal expansion of consciousness, including, say, ancestral experiences, post-incarnation experiences, phylogenetic experiences;

- Spatial expansion of consciousness, including identification with other persons, animal and plant identification, planetary consciousness, consciousness of inorganic matter, out-of-body experiences, etc.;

- Spatial constriction of consciousness - to an organ or cellular substances;

- Experiential extension beyond the framework of "Objective Reality": experiences of other universes and encounters with their inhabitants, archetypal experiences and complex mythological sequences, intuitive understanding of universal symbols, activation of the chakras, consciousness of the universal Mind, the supracosmic and metacosmic void (Grof, 1994).

Transpersonal phenomena continuum ends with the Mind level (K. Wilber). Wilber regards the idea of the "sacred" part of consciousness being identical to the absolute and ultimate reality of the universe known as Brahman, Dao, Dharmakaya, Allah, God, etc. as the core of the perennial philosophy. In general tradition, Mind is that what exists and all that exists, it is beyond space and, therefore, boundless, it is beyond time and, therefore, perennial, there is nothing beyond it.

At this level, human being identifies himself with the Universe, with everything, or rather it is Everything. According to the perennial phi- losophy, this level is a non-ordinary state of consciousness, or rather it is the only real state of consciousness... all the rest turn out to be illusory... (Wilber, 1999) In fact, the subject of psychology has reached its utmost. Like annual rings of the Life Tree, the five rings of expansion of the subject of psychology lead to its utmost maturity, and the five branches with a vast number of branchlets and leaves boggle imagination with their power and realizedness.

Perhaps, some readers got the impression that the author dedicated his article to revealing evolutionary development of the subject of psychology and that psychology has drawn to its humanistic and transpersonal peak and that expansion of the subject of psychology is its true way. With all my love of the theory of paradigm evolution developed by Thomas Kuhn, I cannot agree with his understanding of cycles. From his point of view, paradigm (greek " $\pi \alpha \rho \alpha \delta \varepsilon i \gamma \mu \alpha$ ", i.e. example, sample) is a scientific achievement that is determining the scientific model for some time. According to Kuhn (Kuhn, 1962), each science goes through various paradigmatic cycles. The cycle consists of:

1) preliminary phase: different scientific approaches emerge within the framework of one and the same school;

2) normal science phase: a significant discovery or scientific achievement makes the branch of science get ahead. And scientific theses that are incompatible with existing ones or digress from them are repeatedly placed on trial;

3) revolutionary science phase: a new paradigm replaces the old one.

No doubt, science does not progress via a linear accumulation of new knowledge, but instead undergoes periodic revolutions, in a sense there is some sort of a rise and fashion for ideas and experiment, words. But it is always a problem to discover the rise of a science outside the yoke of some forced convention. Indeed, in terms of their essence, contents, and functions, many psychological maps are also very similar to shaman's worlds, which appeared prior to Buddhism, Christianity, Islam, Mithraism, and Paganism in Slavic and European worlds. All world religions have kept in their reality cartographies the idea of "lower" (hell, satanic host, moral indifference), "upper" (heaven, powers of the Good and the Light, highest virtues, the Light) and middle (everyday vale of human existence) shamanic worlds. This might make a professional psychologist or psychotherapist (the article is dedicated to them) think of an 
analogous psychoanalytical paradigm - Z. Freud's Id, Super-Ego, and Ego (Freud, 1991a).

As to psychoanalytical techniques and methods, what is the strategic difference between Anna O.'s harking back to her repressed recollection of her wish to dance while her father was lying on his dying bed and shaman's journey to a spirit of the dead? And who are they - the two young boys, friends initiating a young Fräulein Anna O. into a non-ordinary state of consciousness (hypnosis) like two inexperienced shamans who don't know what they do. I wrote "inexperienced" because in some cases the shamanic healing practice is more sophisticated than psychotherapy. At least shaman never rejected his own method (unlike Freud did in relation to hypnosis), and their clients never had hysterical pregnancy (like in Anna O.'s case) and global nervous breakdown.

And as to the emergence of the paradigm, it might be just an interpretation of old ideas into modern language, some kind of retranslation - if it meets an empathetic social community and a founding father (founding fathers) of the paradigm has sufficient managerial skills and expansive energy, then we can nominally designate this caesarean section from the womb of perennial philosophy as a "new" method of reality conceptualization - a new paradigm.

I have a strong belief that transformation of psychology and its theoretical innovations originates from contacts with the universal culture of mankind. And it is just ignorance of this great space of meanings and knowledge that can lead to a strange state of being charmed by novelty, which, indeed, is the main suffering of Europe-centered and UScentered psychology and psychotherapy. It reminds me of an infantile interest of a child in his excrements. The world is wider.

As far as the revolutionary science phase is concerned, when a new paradigm replaces the old one, Kuhn, perhaps the then a young hippie, soon believes what he desires. Paradigms do not die. In fact, everything is quite the other way. All five trends, paradigms, of psychology exist and coexist right now, at once. And I would not say that this coexistence is peaceful and empathetic. In the general case, one can find out that psychology of any level will accept and acknowledge potentiality of all the levels that are above its own, but reject existence of all the levels that are below its own, declaring these deeper levels pathological, illusionary or non-existent at all. And I think that it is a great good that there are numerous subjects and numerous understandings of psychology. Though, from the point of view of integrative psychology, it is absurd. But it is the very diversity, competition, struggle, even pride and contempt that create the tension that encourage evolution of psychological science.

\section{Communicative methodology}

We can define the goal of the sixth wave of psychology, a communicative one, as the development of a universal language environment, like mathematical or physics language, within the framework of which any symbol is interpreted unambiguously irrespective of a paradigm.

Communicative methodology (V.A. Mazilov) implies cooperative interaction between sciences, schools, and trends in order to address specific issues of psychotherapy and other human sciences. In this context, V.A. Mazilov seems to be perfectly right noting that it is necessary today to focus every effort so as to work out a scholarly apparatus that would allow correlating different concepts in reality and, therefore, would encourage mutual understanding within the framework of scientific psychology (Mazilov, 2007). A primary specific task is to develop a model of psychological science methodology oriented to communication, i.e. the one that implies improvement of feasible mutual understanding:

- between different trends within the limits of scientific psychology itself;

- between academic, scientific psychotherapy and practice-oriented concepts;

- between scientific psychotherapy and the branches of psychotherapy that do not fall under any traditional academic science (transpersonal, religious, mystic, esoteric, etc.);

- between scientific psychotherapy and arts, philosophy, and religion.

- between psychotherapies that objectify different levels of mental structure: personal, interpersonal and transpersonal (Kozlov, 2005).

\section{Integrative psychology}

In my view, communicative methodology is an essential stage for the emergence of the seventh wave - integrative psychology (K. Wil- 
ber, V.V. Kozlov), which means consolidation of various areas, schools, trends, levels of human science within the semantic field of psychology (Kozlov, 2007; Wilber, 1999).

Modern state of psychology reminds me of construction of the tower of Babel. Having meant to reach and gain insight into the Soul and the Spirit, psychologists, eventually, started to speak different languages and all energy intended for the Great Subject of psychology was spent on stupid disputes and research of brick, dust, and ashes.

Psychologists are still nursing the intention to gain insight into the Soul, yet there are no solidarity of energy and mutual understanding.

We can say that there are five basic models of psychology with their own principles, methodology, subject, and five crystal balls, five lenses through which psychologists of each clan perceive reality in their peculiar way (Kozlov, 2007).

And now efforts of the seventh wave of psychology (integrative one) are focused on setting up interaction between these lenses, crystal balls, in order to create, to design a perfect lens system that adequately reflects mental reality.

Integrative psychology implies maximizing opportunities of a dialogue between representatives of all five trends of psychology, which enables broadening of outlook on approaches and research methodologies used for studying mental reality.

This dialogue means switching on identification mechanisms, empathy and reflection as requirements for understanding of representatives of all five waves of psychology and for creation of efficient interaction between them, which is subject to the common goal - making knowledge of the essence of psyche more profound and discovering new ways and means of cooperation.

Instead of viewing physiological psychology, psychoanalysis, behaviorism, existential-humanistic and transpersonal psychologies as rival approaches, we can view them as complementary ways of making new discoveries related to human being, each of which is potentially informative for the other.

The strategy of integrative psychology is to gain insight into human nature through integration accompanied by critical reflection, synthesis of various traditions, approaches, logics, diagnostic and psychotechnical instruments, yet their autonomy is to be kept for further development.
Its essence is in multiplanar, multidimensional, multilevel, all-vector analysis that allows for qualitatively different research, in which analysis includes such aspects as multiplicity, interlocution, multidimensionality of psychic phenomenon.

Upholding integrative view, which, as a matter of fact, is metasystemic in relation to all five paradigms of psychology, makes objective analysis possible and ensures a new qualitative step in the development of psychological science.

Integrative psychology does not have pretentions to the Truth monopoly with all ensuing consequences, but suggests a new way of dealing with multidimensional knowledge that is associated with the most efficient traditions and their diagnostic, psychotechnic tools.

Methodological basis of the integrative approach involves methodological principles of truth multidimensionality, positivity, relatedness, and ontological pluralism.

Integrative methodology implies that analysis includes findings and achievements of psychological, philosophic, and psychospiritual traditions and approaches that are most effective in a specific phenomenal area of psychology. Integrative psychology involves mechanisms for the development of psychological science, which are understood as: interaction between all waves of psychology, integrative dialogue of alternative approaches, traditions, schools, and critical reflexive positioning.

Integrative approach is a creative and multidimensional synthesis of concepts that objectify various aspects of human activity both in theoretical-methodological and investigatory-psychotechnical respects.

We see the main purpose of psychology in reunion of the holistic structure of mental reality and building of a multidimensional integrative paradigm of modern psychology (Kozlov, 2007).

Each of all five waves of psychology (physiological, psychoanalytical, behavioral, existential-humanistic, and transpersonal) represent:

- a theory, methodology as a system of principles, methods for research of scientific subjects and research culture;

- a psychotechnic impact on this subject;

- representatives of a paradigm who support the wave.

Within the framework of the integrative model, we view personality and groups as complex, open, multicomponent systems able to keep homeostasis, rational interaction with environment, and capable of ad- 
aptation, self-development and generation of new structures and subsystems depending on a situation and new living conditions.

As for the level organization of mental reality, at a first approximation we can point out persona, interpersona, and transpersona, which fully cover all possible phenomenology of human psyche (starting from physiological and somatic to a transpersonal one) both in individual and group forms.

Individual free consciousness interacts with these three subsystems giving them substance and ensuring problematization of some relationships between global subsystems or relationship and tension inside systems themselves.

Each global system (persona, interpersonal, and transpersonal) has three components classes (material, social, and spiritual).

Thus, at a second approximation we can point out nine basic constructs with systemic ties between them, and they are both the subject of research and the subject of influence and transformation:

Persona - material Ego, social Ego, and spiritual Ego.

Interpersona - forms of social consciousness and unconsciousness and their actualization on material, social, and spiritual levels - materia Interpersona (object-material decoration of social statuses and roles) social Interpersona (a system of interactions and relationships determined by status-role identifications in social communities), spiritual Interpersona (a system of ethical and existential values and standards of social communities).

Transpersona - material Transpersona (object-material representations of spiritual attributes - starting from a brass christcross and primitive yantras to monastic complexes and pyramids), social Transpersona (social decoration of spiritual traditions and religions - starting from binary relationships between guru and his disciple to social organization of world religions), spiritual Transpersona (true transpersonal experience numinous and sacral both for individuals (for example, Sattori) and groups (group induced religious ecstasy)).

All nine substructures have unique and very sophisticated systemic organization that each time requires a special analysis of both structural and processual-dynamic aspects.

At a third approximation we can point out a global Not-Self system and nine basic constructs with systemic ties between them, which are a negative mirror reflection.
When dealing with a client, integrative approach relies on the highest ethical values invariant for all cultural communities. Spiritual traditions designated them as non-involvement, impartiality (wei wu-wei in Taoism), Mahakaruna (Great Compassion) with the four precious states of mind (joyfulness, truthfulness, compassion, loving kindness) in Buddhism, neighbourly charity and mercy in Christianity, i.e. the ethical core of the integrative approach is composed of the highest moral priorities elaborated in spiritual traditions.

Apart from being explanatory and conceptual, the goal of integrative psychology is quite pragmatic - to change structures and forms of human consciousness of man, who, eventually, discovers ability to think, reflect, and act adequately in this or that socio-cultural environment. Therefore, at the essential level, it is important for us to ensure transformation of homo sapiens and homo habilis (man of reason and ability) into homo ludens and homo creacoficus (man the player and the doer of wisdom). Particularly, we would like this transformation to occur in bearers of knowledge on human being: psychologists and psychotherapists, philosophers and psychiatrists, educationalists and social workers.

The principle of wholeness is the world view eye of integrative methodology. The notions of "integrative approach" and "integrative personality" have long been used by different trends and schools of psychotherapy: from gestalt and humanistic psychotherapy to our Russian trends (cultural-historical, activity approaches, etc).

Perhaps, the very notions of "aim" and "the whole" have etymologi-

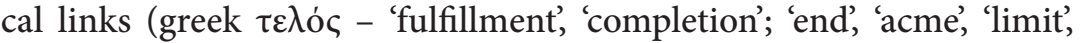
'purpose'; $\tau \varepsilon \lambda \varepsilon$ เó $\varsigma$ - 'complete, 'full', 'accomplished'; 'final', 'utmost', 'perfect').

At the same time, goal achievement means completion of the action, closing the circle, ascent to fullness, perfection, and beauty. We view wholeness as a central psychological category synthesizing the objective and subjective, and at the level of individual free consciousness we recognize it to be the utmost possible degree of integration that can be related to the Universe reality.

According to integrative approach, human personality is the highest actual form of systemic wholeness, and the backbone of its functioning is individual free consciousness. Integrative psychology upholds the idea of necessary comprehensive study of personality as a system 
all the elements of which are interrelated and interdependent. Thus, both emphasis and individual study of some elements is possible only in the abstract. A goal, wholeness, can only be achieved in case a perfect symmetrical whole is formed. We can speak about a more holistic understanding of what man and his consciousness are just today, at the beginning of the third millennium, when the storehouse of knowledge on human psyche is increased not only at the expense of purely scientific research (in a general sense), but also at the expense of esoteric and spiritual knowledge that has always been secret.

In my view, we can observe lately crystallization of two most important streams in psychology - methodology and understanding of subject of psychology itself. As far as methodology is concerned, more than once we dwelled in our publications on integrative methodology and even integrative psychology being "superpsychology" capable of linking all the levels and aspects of psyche functioning. In my opinion, in terms of subject of psychology, after working on "the unconscious", "behavior", "thinking", "gestalt", "activity" and many other words and psychological categories we came to crystallization of the original understanding of the subject - "psyche" as "soul-mind", or more accurate and contemporary notion of "individual free consciousness".

The grounds for modern scientific psychology are generally known: they are common for all principles of natural sciences that were already stated by Rene Descartes in his "Metaphysical Meditations". That is where definitions of psyche and psychology derive from. Textbooks and dictionaries define psychology as a science studying processes of man's active reflection of objective reality in the form of sensations, perception, thinking, emotions, and other psyche processes and phenomena or as a scientific study of laws of development and functioning of psyche as a specific form of life activity. As far as subject of psychology is concerned, it is basically facts, laws, mechanisms of psyche, and psyche is defined as a form of active reflection of objective reality which emerges when highly organized living beings interact with the outside world and it performs a regulative function regarding their behavior (activity).

We should note that scientific psychology inevitably came to its crisis for reasons implicitly existent from the very beginning. Emergence of integrative psychology is in many ways determined by the crisis of modern scientific psychology, which failed to fulfill a large public order for methods of personal therapy, personality growth, transcendental experience, regular and situational crisis states, and a wide range of states of consciousness. The need for integrative psychology also arose due to the fact that scientific psychology ignored interpersonal (conscious and unconscious aspects of social consciousness) and transpersonal experience.

No doubt, transpersonal psychology made a great move in psychology returning to its subject and, which is most important, to spiritual and existential problems of human life. Transpersonal experience is man's experience of transcending his Ego, time, and space, of the return to the cultural and historical past of man and the world. It is as if man recollects episodes from the history of his life on the Earth. Thus, it is an evidence of man being able to easily journey in any time, any world, micro- or macrocosm. According to S. Grof, it is clear that we need a new psychology, which is more relevant to the modern level of consciousness research and complementary to the cosmos image, which is being formed in our minds thanks to the latest advances in natural science (Grof, 1994).

Integrative psychology aims at both studying individual manifestations of human psyche and at an attempt to comprehend the nature of man in general - in a broad worldview context. It is focused both on universal psyche phenomenology maps and on experimental studies of states of individual free consciousness, which unpack the contents of persona, interpersonal, and transpersona. Let us put forward theses that will help us distinguish integrative psychology from other trends:

1. Integrative psychology as a scientific discipline relies on psychophysiology, psychophysics and on neurophysiological individuality model by structuring such notions as mental functions, temperament, character, motivation, etc. Psychophysics and neurophysiological processes, including somatic ones, are rather considered to be the environment where individual free consciousness is dipped into. Physiology (including neurophysiology) is a maintenance system rather than a system generating psychic phenomena.

2 . The core of psychic organization is individual free consciousness, which I. Kant called transcendental apperception. It is an a priori unity of self-consciousness that makes any knowledge possible. Thus, transcendental apperception is a transpersonal form of consciousness. 
3. Scientific psychology failed to overcome psychophysical and psychophysical parallelism. It appears that it was in many ways the result of original dualism inherent in scientific view of the world of the old paradigm: division into the material and the ideal (spiritual) and into subject and object. Integrative psychology is beyond this dichotomy - it is the same as consciousness functioning in the environment which is beyond the differences between subject and object when there is a direct experience of unity of the cognizing and the cognizable. Dual view of the world in scientific psychology is opposed to monism of integrative psychology postulating, in particular, the unity of the world and man. Consequently, there are higher levels of integration and wholeness in any personality.

4. Within academic psychology, the notion of "psyche" is closely linked to the category of "individual", while within integrative psychology the key category is "consciousness" with a broader semantic field focused not solely on an individual. Consciousness is characterized by universality, multiplicity of levels, states, forms, openness, and selfmotion.

5. Psychology as a science follows the structural principle, based on which it explains mental processes. Integrative psychology represents an energetic consciousness model that has a lot of potentialities both for practical psychology and for its theoretical developments. At the same time phenomena of transpersonal psychology that fall into the category of parapsychic or super abilities are also under consideration of classic psychological ideas updating data on the nature of mental processes and functions.

6. Integrative psychology should be identified neither with numerous schools (philosophic, psychological, spiritual) objectifying levels and forms of persona functioning nor with numerous schools objectifying levels and forms of social consciousness functioning nor with numerous schools objectifying levels and forms of transpersonal experience functioning. It is not because integrative psychology is neither of these three, but because it is either of these three.

7. The subject of integrative psychology is studying both experiences of non-ordinary (altered) states of consciousness and so-called "transitional states" of human psyche - from experience of holotropic, individualized, split, atomic consciousness pattern (regarding both outside and inner worlds) to states of expanded consciousness, which are whole in their perception of both one's own self and the world; from the state of struggle, destruction, and negation to the state of unity, consolidation, cooperation with one's own self, other people, and with the whole world. Besides, the subject of integrative psychology is studying such transitional states as conflicts (external and internal), unconscious impulses, alienation from one's own self and the world, incapability of creative work, love, cooperation, psychosomatic diseases, and various neuroses. Integrative psychology views all these states as various environments for actualization of consciousness in personality, and they have real potential to overcome their negative aspect and develop into their opposite. This leads to a conceptually important point of integrative psychology, from which it appears in its application aspect as psychology of development, personality "ascent" to its own self - to a higher integration of individual consciousness. And in this point the "ascent", "personality growth", "spiritual self-improvement", "higher" and "lower" levels are rather an absurd of reality differentiation, and all concepts about them (philosophic, psychological, spiritual, religious, scientific, metaphysical, etc.) are just a game of consciousness.

The conceptual field of integrative psychology does not exclude conceptual fields of other psychologies, but can result in review of not only notions, but also deep knowledge on the nature of man, psyche, and consciousness.

Integrative psychology relies on several essential theses:

- monism as the unity of man and the world (spiritual and bodily, finite and eternal);

- holism as the idea of primordial integrity of human consciousness;

- vitality of consciousness;

- capability of self-motion and self-development - requiring no external control;

- the idea of meeting crises on the way to convergence, cooperation, and complementarity of all sides of mental life in individual free consciousness, which are opposed and viewed as problem by Ego and social consciousness.

If we search for the subject of integrative psychology in studying ways to transpersonal experience, expanding consciousness and developing individual's personality, and meeting crises on the way to spiritual and other kind of growth, we can say that the integrative approach can 
help us not only solve this task theoretically, but also analyze already existing psychotechnologies, as well as generate new methods of psychology adequate for its subject.

\section{References}

Campbell, J. (1997). Geroj s tysyachyu licami [The hero with a thousand others]. Kiev: Sofiya.

Feydiman D., Freyger R. (1996). Teoriya i praktika lichnostno-orientirovannoj psikhologii. Metodika personal'nogo i social'nogo rosta [Theory and practice of personality-oriented psychology. The method of personal and social growth]. 1, 2. Moskva: Tri L.

Frankl, V. (1990). Chelovek v poiskakh smy 'sla [Man in search of meaning]. Moskva: Progress.

Freud, Z. (1991a). Vvedenie v psikhoanaliz: Lekcii [Introduction to psychoanalysis: Lectures]. Moskva: Nauka.

Freud, Z. (1991b). Tolkovanie snovidenij [Interpretation of Dreams]. Kiev: Zdorov'ya.

Fromm, E. (1993). Psikhoanaliz i e'tika [Psychoanalysis and Ethics]. Moskva: Respublika.

Grof, S. (1994). Za predelami mozga: rozhdenie, smert' i transcendenciya $v$ psikhoterapii [Beyond the brain: Birth, Death and Transcendence in Psychotherapy]. Moskva: TP

Huxley, A. (1997). Vechnaya filosofiya [The eternal philosophy]. Moskva; Kiev: Relf-buk - Vakler.

James, W. (1993). Mnogoobrazie religioznogo opy 'ta [The multiplicity of religious experience]. Sankt-Petersburg:Andreyev and Sons.

Jung, K. (1994). Psihologiya bessoznatel'nogo [Psychology unconscious]. Moskva: Kamon.

Kozlov, V.V. (2000). Duhovnye stranstviya [Spiritual Journeys]. Jaroslavl': MAPN.

Kozlov, V.V. (2003). Rabota s krizisnoj lichnost'yu. Metodicheskoe posobie [Dealing with identity crisis. Toolkit]. Moskva: Izdatel'stvo Instituta psihoterapii.

Kozlov, V.V. (2005). Psikhotehnologii izmenennykh sostoyanij soznaniya. Lichnostny j rost. Metody i tekhniki [Psychotechnologies altered states of consciousness Personal growth. Methods and techniques]. Moskva: Izdatel'stvo Instituta psihoterapii.

Kozlov, V.V. (2007). Integrativnaya psikhologiya: Puti dukhovnogo poiska, ili osvyashhenie povsednevnosti [Integrative Psychology: Path of spiritual searching, or sanctification of everyday life]. Moskva: Psihoterapiya.

Kozlov, V.V., Bubeev, Yu.A. (1997). Izmenennye sostoyaniya soznaniya:psikhologiya i fiziologiya [Altered states of consciousness: psychology and physiology]. Moskva.
Kuhn, T.S. (1962). The Structure of Scientific Revolutions. Chicago: University of Chicago Press.

Maslow, A. (1997). Psikhologiya by 'tiya [Psychology of Being]. Moskva: Relf-buk.

Maykov, V.V., Kozlov, V.V. (2004). Transpersonalnaya psikhologiya: Istoki, istoriya, sovremennoe sostoyanie [Transpersonal psychology: Origins, history, current state]. Moskva: AST.

Mazilov, V.A. (2007). Metodologiya psikhologii: Uchebnoe posobie [The methodology of psychology: A manual]. Yaroslavl: MAPN.

McKenna, T. (1995). Pishha bogov: poisk pervonachal'nogo dreva znaniya [Ambrosia: the initial search tree of knowledge]. Moskva: TPI.

Michelet, J. (1993). Korni soznaniya [Roots of consciousness]. Kiev: Sofiya.

Nalimov, V.V. (1989). Spontannost' soznaniya: Veroyatnostnaya teoriya smyslov $i$ smyslovaya arkhitektonika lichnosti [Spontaneity of consciousness: Probability theory of meaning and semantic architectonics of personality]. Moskva: Prometej.

Rogers, K. (1997). Klientocentrirovannaya terapiya [Customer directed therapy]. Moskva; Kiev: Relf-buk; Vakler.

Wilber, K. (1999). Proekt Atman: transpersonal 'nyj vzglyad na chelovecheskoe razvitie [Atman Project: transpersonal perspective on human development]. Moskva: TPI.

Yalom, I. (1999). E'kzistencial 'naya psikhoterapiya [Existential psychotherapy]. Moskva: Klass. 